\title{
Bumblebees Perform Well-Controlled Landings in Dim Light
}

\author{
Therese Reber*, Marie Dacke, Eric Warrant and Emily Baird \\ Department of Biology, Lund University, Lund, Sweden
}

To make a smooth touchdown when landing, an insect must be able to reliably control its approach speed as well as its body and leg position-behaviors that are thought to be regulated primarily by visual information. Bumblebees forage and land under a broad range of light intensities and while their behavior during the final moments of landing has been described in detail in bright light, little is known about how this is affected by decreasing light intensity. Here, we investigate this by characterizing the performance of bumblebees, $B$. terrestris, landing on a flat platform at two different orientations (horizontal and vertical) and at four different light intensities (ranging from $600 \mathrm{~lx}$ down to $19 \mathrm{~lx}$ ). As light intensity decreased, the bees modified their body position and the distance at which they extended their legs, suggesting that the control of landing in these insects is visually mediated. Nevertheless, the effect of light intensity was small and the landings were still well controlled, even in the dimmest light. We suggest that the changes in landing behavior that occurred in dim light might represent adaptations that allow the bees to perform smooth landings across the broad range of light intensities at which they are active.

\section{OPEN ACCESS}

Edited by:

Martin Giurfa,

CNRS - Université Paul

Sabatier-Toulouse III, France

Reviewed by:

Daniel Tomsic,

University of Buenos Aires, Argentina Paloma Tamara Gonzalez-Bellido, University of Cambridge, UK Stéphane Viollet, Aix-Marseille University, France

*Correspondence: Therese Reber therese.reber@biol.lu.se

Received: 05 April 2016 Accepted: 30 August 2016 Published: 13 September 2016

Citation:

Reber T, Dacke M, Warrant E and Baird E (2016) Bumblebees Perform

Well-Controlled Landings in Dim Light.

Front. Behav. Neurosci. 10:174. doi: 10.3389/fnbeh.2016.00174
Keywords: bumblebee, Bombus terrestris, insect, landing, flight, vision, light intensity, behavioral adaptation

\section{INTRODUCTION}

To ensure a safe and smooth landing, a flying insect has to regulate its speed, modify its body posture and extend its legs in good time before making contact with the surface. Previous work has shown that, in a diverse range of insects, visual input is important for controlling these components of the landing behavior (flies: Wagner, 1982; Borst, 1986; Tammero and Dickinson, 2002; van Breugel and Dickinson, 2012; honeybees: Srinivasan et al., 2000; Baird et al., 2013; bumblebees and sweat bees: Baird et al., 2015). To make a smooth touchdown, these insects must therefore be able to reliably discriminate the surface from the background. As light levels fall, this task becomes more challenging because contrast discrimination becomes increasingly difficult. This is, in part, due to the low number of photons that are available and the fact that they arrive at the retina in a random and unpredictable way (Warrant and McIntyre, 1993). This random arrival of photons causes visual "noise" that degrades the reliability of vision (Rose, 1942; De Vries, 1943). Transducer noise (Lillywhite, 1977, 1981; Lillywhite and Laughlin, 1979; Laughlin and Lillywhite, 1982) and dark noise (Barlow, 1956) further add to the unreliability of vision at low light levels.

Despite the challenges imposed by the dim light on visually controlled behaviors, many insects fly and land successfully at night. Two of them are the nocturnal sweat bee Megalopta genalis and the Indian carpenter bee Xylocopa tranquebarica (Warrant et al., 2004; Kelber et al., 2006; Somanathan et al., 2008). This is remarkable, 
considering that bees have apposition compound eyes, an inherently inefficient design for collecting light. To adjust to their nocturnal lifestyle, these two bee species have evolved a number of optical adaptations (larger facets and wider rhabdoms), as well as neural adaptations (spatial summation) to make their visual systems more sensitive (Warrant, 1999; Greiner et al., 2004). Bumblebees also forage early in the morning and late in the evening (Spaethe and Weidenmüller, 2002), suggesting that they possess mechanisms to control their flight under low light conditions. Indeed, bumblebees temporally sum the signals in their photoreceptors (Reber et al., 2015). While such summation would provide a brighter image of the world, the increased visual processing time would limit the ability to detect fast visual motion. As an apparent attempt to reduce the effect of this trade-off, bumblebees fly slower as light levels fall (Reber et al., 2015). By decreasing their speed, the bees increase the likelihood of obtaining sufficient visual information to reliably see motion information and to use this to control their flight in dim light. This behavioral adaptation to dim light has also been observed in honeybees (Rose and Menzel, 1981), hornets (Spiewok and Schmolz, 2005) and moths (Sponberg et al., 2015).

While the behavior of bumblebees and honeybees during the final moments before touchdown has been described in great detail for bright light conditions (Evangelista et al., 2009; Reber et al., 2016), the effect of light intensity on the landing behavior of insects has received little attention. To the best of our knowledge, only one study (Baird et al., 2015) has addressed this by filming B. terrestris, while landing on a vertical surface at the nest under two different light intensities (190 and $19 \mathrm{~lx}$ ). Interestingly, the bees extended their legs significantly later in the dimmer light condition, supporting the hypothesis posed by Reber et al. (2015) that bumblebees use temporal summation to increase light capture and improve visual reliability to control landing in dim light (since a longer integration time might delay the detection of the surface).

Since we now know that the landing behavior of bumblebees varies depending on the slope of the landing surface (e.g., they extend their legs further away from the surface when landing at horizontal compared to inclined surfaces; Reber et al., 2016), the aim of this current study is to obtain a deeper understanding of the effect of light intensity on the control of their landing behavior when approaching platforms of different orientations. To do this, we analyze the behavior of free-flying bumblebees (B. terrestris) landing on a flat (horizontally or vertically oriented) platform at four different light intensities (chosen to reflect natural light conditions ranging from sunrise or sunset on a clear day $(600 \mathrm{~lx})$ down to the middle of civil twilight (19 lx; Johnsen et al., 2006). We investigated the effect of light intensity on the approach trajectory and speed, as well as the position and duration of the hover phase (a short period preceding touchdown when the bees remain stationary in the air). There is reason to believe that the hover phase is affected by light intensity because previous work has suggested that this behavior has a strong visual component. It has been proposed that bees use the hover phase to visually inspect the pollen content (Zimmerman, 1982) or specular reflections from nectar droplets (Kevan, 1976) in flowers in order to evaluate if they are rewarding or not (Goulson et al., 2001). Landing performance is also characterized by the distance from the platform at which the bees extend their legs, the body posture at this moment in time, as well as the time between leg extension and first contact with the surface (time to contact, TTC).

\section{MATERIALS AND METHODS}

\section{Animals and Experimental Setup}

The experiments were performed with six hives of commercially bred bumblebees, $B$. terrestris (Koppert, Netherlands) in a flight cage ( $2.3 \mathrm{~m}$ long, $2.0 \mathrm{~m}$ high and $2.0 \mathrm{~m}$ wide, at $23^{\circ} \mathrm{C}$ ) made from aluminum netting. The bees were trained to visit a feeder filled with sugar solution, placed on top of a flat, horizontally oriented, transparent Perspex platform $(10 \mathrm{~cm} \times 15 \mathrm{~cm}, 0.4 \mathrm{~cm}$ thick) that was attached to a tripod on a rotatable arm and positioned $1 \mathrm{~m}$ above the ground (Figure 1). Once the bees were regularly feeding from the "training feeder", it was removed and they were instead presented with three disks of white filter paper $(3 \mathrm{~cm}$ diameter), saturated with sugar solution and placed in a row along the center-line of the platform (Figure 1). A small disk of blue paper ( $1 \mathrm{~cm}$ diameter) was placed in the middle of each feeder disk to attract the bees to the center. Three disks were used to avoid an excess of bees at the same position. Bees that regularly visited the platform were individually marked with small plastic number plates on the back of their thorax. To discriminate the bees against the background in the camera images, a white cardboard disk ( $30 \mathrm{~cm}$ in diameter) was placed $10 \mathrm{~cm}$ behind the center of the platform.

\section{Experimental Procedure}

Individual landings at the platform were filmed at 400 frames s ${ }^{-1}$ using a high-speed video camera (MotionBLITZ EoSens ${ }^{\circledR}$ mini, Mikrotron GmbH, Germany; image resolution: $1280 \times 600$ pixels; F-number $=1.4$ (focal length $=8 \mathrm{~mm}$, aperture diameter $=5.7 \mathrm{~mm}$ ) placed $16 \mathrm{~cm}$ away from the center of the platform. The platform was rotated to two different orientations measured from the horizontal plane: $0^{\circ}$ and $90^{\circ}$, at four different light intensities: $19 \mathrm{~lx}\left(1.62 \times 10^{13}\right.$ photons $\left./ \mathrm{cm}^{2} / \mathrm{s}\right), 60 \mathrm{~lx}$ $\left(4.30 \times 10^{13}\right.$ photons $\left./ \mathrm{cm}^{2} / \mathrm{s}\right), 190 \mathrm{~lx}\left(1.76 \times 10^{14}\right.$ photons $\left./ \mathrm{cm}^{2} / \mathrm{s}\right)$, and $600 \mathrm{~lx}\left(5.64 \times 10^{14}\right.$ photons $/ \mathrm{cm}^{2} / \mathrm{s}$; as measured at the platform [lx measurements: Hagner ScreenMaster, B. Hagner, Sweden; photons $/ \mathrm{cm}^{2} / \mathrm{s}$ measurements: QE65000, Ocean Optics Inc., Dunedin, FL, USA]). Light was provided by two dimmable fluorescent lamps (flicker frequency $>20 \mathrm{kHz}$, BIOLUX $^{\circledR}$, OSRAM GmbH, Germany) attached to the ceiling of the cage. These lamps have a broad daylight spectrum with peaks at $450 \mathrm{~nm}, 545 \mathrm{~nm}$, and $610 \mathrm{~nm}$, as well as in the UV (UVC $<2 \mu \mathrm{W} / \mathrm{klm}, \mathrm{UVB}<20 \mathrm{~mW} / \mathrm{klm}$, UVA $<150 \mathrm{~mW} / \mathrm{klm}$ ). To achieve the darkest light level (19 lx), the lamps were further dimmed with neutral density filters (210 0.6 ND, LEE Filters, UK). In the darker conditions, infrared illumination 


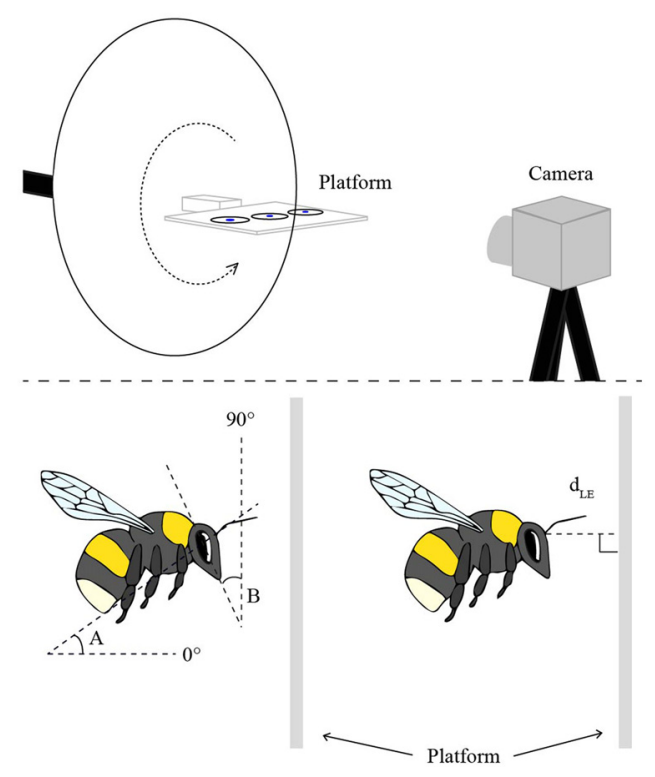

FIGURE 1 | The experimental setup (top), in which the bees were trained to visit a flat Perspex platform with three disks of white filter paper saturated with sugar solution. Landings on the platform were filmed from the side with a high-speed camera. In order to film landings at different platform orientations, the platform was attached to a rotatable arm (dotted arrow). The schematic illustrations of the bees (bottom) indicate the two angular measurements of body posture (angles A and B) and the linear measurement of the distance to the platform at leg extension $\left(d_{L E}\right)$.

(peak wavelength: $850 \mathrm{~nm}$, which is invisible to the bees) was used to discern the bees in the videos. Before each 1-h long experimental trial, the bees were given $30 \mathrm{~min}$ to adapt to the new light intensity. All experiments were conducted between 08:00 and 14:00, when the bees were most active. To avoid any circadian influence on the landing behavior, the trials were pseudo-randomized throughout the experiment. Only bees that landed alone on a feeder disk were used in the analysis to avoid any disturbance from other bees.

\section{Analysis}

The Hover Phase, Time to Contact, and Flight Speed

To visualize the flight trajectories and analyze the bees' position over time, seven individual landings at each platform tilt (and light intensity) were manually digitized with a custom made tracking software in Matlab (Mathworks Inc., Natick, MA, USA). These trajectories allowed us to examine the distance between the bee and the platform during the hover phase (the short period just before touchdown, during which the bees were almost $[ \pm 1 \mathrm{~mm}]$ stationary in the air), the duration of the hover phase, the TTC (defined as the time between start of leg extension and touchdown), and the mean flight speed (just before the hover phase, as well as just before touchdown). For analysis of the distance between the bee and the platform during the hover phase, a mean value of this distance at the start and at the end of the hover phase was used. Flight speed was calculated by dividing the two-dimensional distance each bee traveled between two successive frames by the time between two frames $(1 / 80 \mathrm{~s})$. The frame rate used in the speed calculation was 80 frames $s^{-1}$ because the bees were tracked every five frames. Flight speed was further analyzed at two different time points: $10 \mathrm{~ms}$ before the hover phase, and $10 \mathrm{~ms}$ before touchdown. At each time point, a mean value of the flight speed over $25 \mathrm{~ms}$ was used.

\section{Body and Head Orientation and the Distance to the Platform at Leg Extension}

The body and head orientations and the distance of the bee to the platform were determined in the frame $(2.5 \mathrm{~ms})$ prior to the frame in which the bee started to extend its legs in preparation for contact with the platform. Only bees that landed in side view (or nearly so) were used in the analysis. In the selected frame, for each bee, two angles were measured (using Screen Protractor 4.0, Iconico, Inc., New York, NY, USA): angle A between the long axis of the body and the horizontal plane, and angle B between the vertical plane and a line drawn from the top of the head through the tip of the mouth (for schematic illustrations of these measurements, see Figure 1). The perpendicular distance between the base of the antennae and the landing surface $\left(\mathrm{d}_{\mathrm{LE}}\right)$ was also measured for each frame (using ImageJ $1.47 \mathrm{v}$, Wayne Rasband, National Institutes of Health, Bethesda, MD, USA; Figure 1).

\section{Statistics}

All statistical tests were performed using SPSS (IBM SPSS Statistics 20, USA). Two-way ANOVAs were conducted for each data set to examine if there was an interaction between platform tilt and light intensity on all the different measurements in this study. If a significant interaction was found, a one-way ANOVA was conducted for each platform tilt to examine the effect of light intensity. If no interaction was found, post hoc tests (LSD) were performed on the effect of light intensity.

\section{RESULTS}

\section{Distance to the Platform During the Hover Phase and the Duration of the Hover Phase}

Figures 2, 3 show the position and speed, respectively, of landing bumblebees during the last $300 \mathrm{~ms}$ before touchdown. During this time interval, the bees hovered for a short period before extending their legs (marked with $\mathrm{X}$ in Figure 2). To investigate the ability of the landing bees to assess the distance to the platform in dim light, we examined the distance between the bee and the platform during the hover phase at two different platform orientations $\left(0^{\circ}\right.$ and $\left.90^{\circ}\right)$ and at four different light levels $(19,60,190$ and $600 \mathrm{~lx})$. We found that the distance was significantly shorter for the vertical platform than for the horizontal platform, i.e., the bees hovered closer to the vertical platform (Figure 4A, Table 1). However, we found no significant effect of light intensity on hover distance (Table 1), indicating that, even in dim light, bumblebees are able to perform wellcontrolled landings. One way that they might achieve this is to increase the time that they spend in the hover phase, a strategy 
that would allow their visual system time to collect more light and increase visual reliability before contacting the surface. We therefore analyzed the duration of the hover phase preceding touchdown, but found that this was not significantly affected by either platform tilt or light intensity (Figure 4B, Table 1). Thus, hover phase duration does not appear to be modified to provide a gain in visual reliability in dim light.

\section{Distance to the Platform at Leg Extension, Time to Contact and Flight Speed}

Another way to facilitate landing in dim light might be to extend the legs earlier-a safety measure that would allow the bees to account for errors in estimating the distance to the platform. To investigate if bumblebees employ this strategy, we measured the distance from the platform at which leg extension was initiated (for examples of flight trajectories with the timing of leg extension indicated, see Figure 2). We found that the bees extended their legs significantly further away from the platform as light intensity decreased from $600 \mathrm{~lx}$ to $60 \mathrm{~lx}$ in preparation for a touchdown on the $90^{\circ}$ platform, while light intensity had no measurable effect when the platform tilt was $0^{\circ}$ (Figure $4 \mathrm{C}$, Table 1).

To further investigate the effect of light intensity on the timing of leg extension, we also analyzed the TTC, defined as the time between leg extension and first contact with the surface. We found that light intensity affected TTC, but that the effect was different for the two platform tilts (Figure 4D, Table 1). At $0^{\circ}$, we found a significant increase in TTC as the light intensity decreased from $600 \mathrm{~lx}$ to $190 \mathrm{~lx}$. However, we found no difference between $600 \mathrm{~lx}$ and $60 \mathrm{~lx}$, or between $600 \mathrm{~lx}$ and $19 \mathrm{~lx}$ (Table 1). At $90^{\circ}$, TTC increased in a more linear fashion as light levels fell (Table 1). This could either be an effect of the earlier leg extension observed above (an extension of the legs further away from the platform will result in a longer TTC if the bees are moving at the same speed) and/or due to a decrease in the approach speed of the bees. To investigate if the bees reduce flight speed during landing in dim light, we measured the mean flight speed of the bees just before the hover phase ( $\left.\nu_{\mathrm{BHP}}\right)$, as well as just before touchdown $\left(v_{\mathrm{BTD}}\right.$; to see how flight speed varied over time during landing, see Figure 3), but found no effect in either case (Figures 4E,F, Table 1).

\section{Body and Head Orientation at Leg Extension}

To investigate the effect of light intensity on landing posture, we analyzed the body and head orientation of the bees just before leg extension. The angle between the body and the horizontal plane (angle A) was significantly larger for the vertical platform than for the horizontal platform, i.e., the bees tilted their body more vertically when landing on the vertical surface (Figure 4G, statistical details in Table 1). Similarly, as light levels decreased from $600 \mathrm{~lx}$ to $19 \mathrm{~lx}$, the body angle significantly increased when landing at both platform tilts (Figure 4G, Table 1), i.e., the bees flew in a more upright posture as light levels fell.

The angle between the head and the vertical plane (angle B) was also larger for the vertical platform than for the horizontal platform, indicating that the bees approached the vertical platform with their head in a more horizontal orientation (Figure 4H, Table 1). Furthermore, as light intensity decreased, the head angle also increased significantly except when comparing the orientations at $600 \mathrm{~lx}$ and $60 \mathrm{~lx}$ (Figure 4H, Table 1). As with body orientation, the effect of light intensity on head orientation was the same for both platform tilts (Table 1).

\section{DISCUSSION}

\section{Light Intensity does not Affect the Hover Phase}

Given that the purpose of the hover phase is to mediate visual tasks (Kevan, 1976; Zimmerman, 1982), it is also reasonable to assume that the initiation of the hover phase itself is controlled using visual cues. If bumblebees do indeed rely on vision to control the distance from the platform at which they initiate the hover phase, then we might expect that this will be affected in dim light due to the reduced reliability of visual information. Surprisingly, the bees hovered at the same distance from the platform regardless of light level (Figure 4A, Table 1), although they hovered closer to the vertical platform $(16 \pm 7 \mathrm{~mm}$, mean $\pm \mathrm{SD})$ than to the horizontal platform $(22 \pm 7 \mathrm{~mm})$. This result is interesting for two reasons. First, it suggests that the bees regulate their hover distance based on the orientation of the platform, most likely due to the different approach angles of the bees required in each case. Second, the lack of effect of light intensity suggests that the visual system of the bumblebees is sensitive enough to accurately assess the distance to the platform at light levels as low as $19 \mathrm{~lx}$. One strategy that would enable the bees to increase the reliability of their distance estimation in dim light would be to increase the duration of the hover phase. However, we found that hover duration remains constant, irrespective of changes in light intensity or platform tilt. It is also possible that hover distance is regulated by non-visual sensory information, such as mechanosensory cues coming from the air flow from the wings being deflected off the platform (it is also important to note that no part of the bee was ever observed to be in contact with the platform during the hover phase). It is not possible from our data to determine exactly what cues bumblebees use to control hover distance, but it is nonetheless remarkable that they are capable of making such fine distance measurements even in dim light.

Interestingly, during landings on the vertical platform and at the two lower light levels (60 and $19 \mathrm{~lx}$ ), the bees were found to extend their legs before they initiated their hover phase (compare Figures 4A,C). This indicates that the hover phase and leg extension are not dependent upon each other, although our data suggest that they are both clearly important components of the landing behavior of bumblebees.

\section{Light Intensity Affects Leg Extension and Time to Contact But Not Approach Speed}

Light intensity affected the distance at which bees extended their legs before landing when the platform was vertical, but 
A
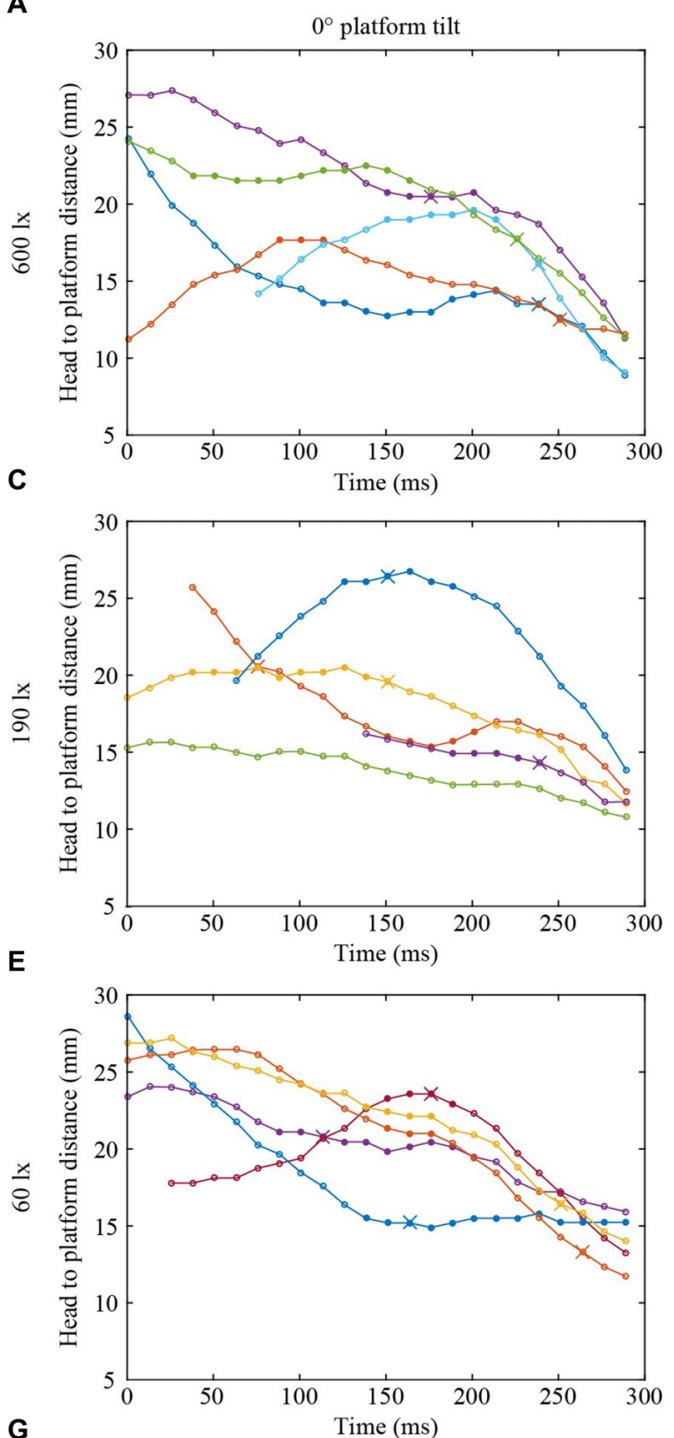

G

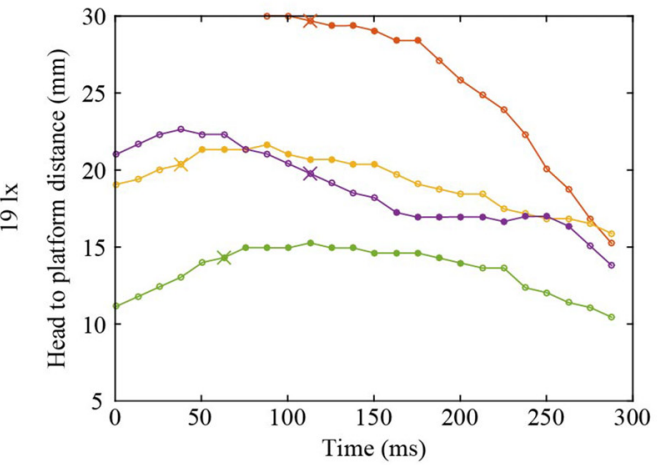

B
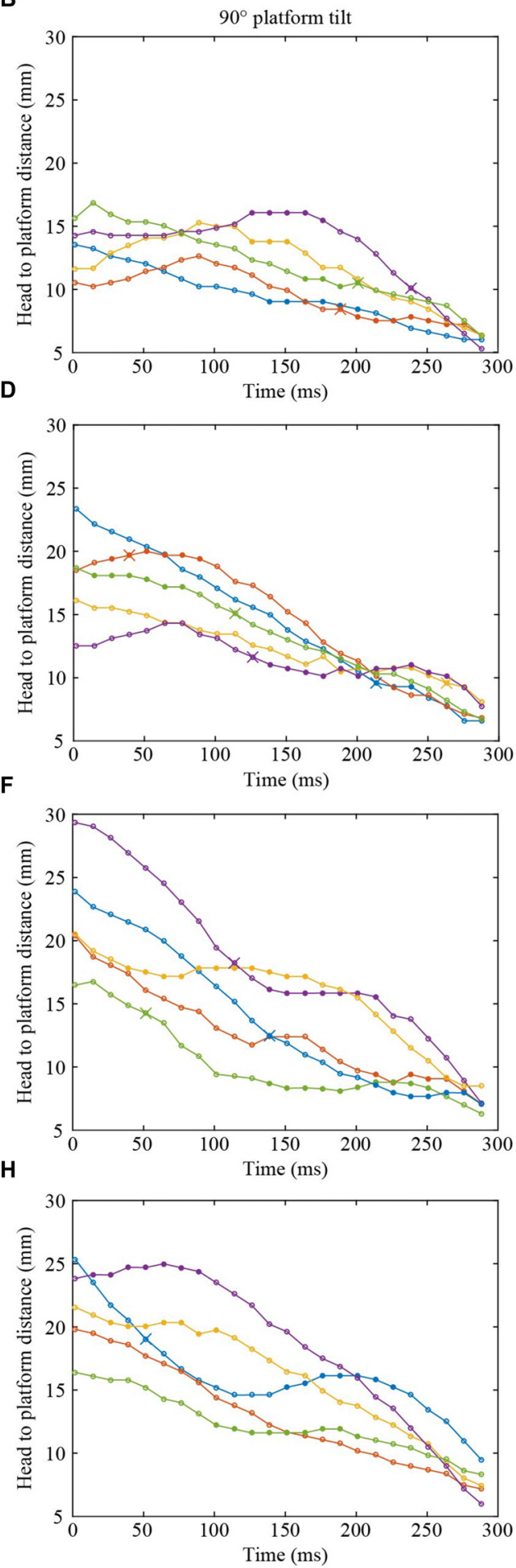

FIGURE 2 | Flight trajectories of landing bumblebees at different light intensities (A,B) $600 \mathrm{~lx},(\mathrm{C}, \mathrm{D}) 190 \mathrm{~lx},(\mathrm{E}, \mathrm{F}) 60 \mathrm{~lx},(\mathrm{G}, \mathrm{H}) 19 \mathrm{~lx}$, and platform tilts $(\mathbf{A}, \mathbf{C}, \mathbf{E}, \mathbf{G}) \mathbf{0}^{\circ}, \mathbf{( B , D , F , H )} 90^{\circ}$. For clarity, only four or five trajectories are shown in each condition. Circles represent the distance between the base of the antennae and the platform surface. Filled circles represent the time spent in the hover phase and crosses indicate the timing of leg extension. Trajectories without a cross represent landings where leg extension occurred outside of the graph window, except the blue line in (B) where leg extension occurred after contact. The last point in each graph indicates when the bee contacted the surface. In each graph, different colors represent different bees, but the same color in different graphs does not represent the same bee. 
A

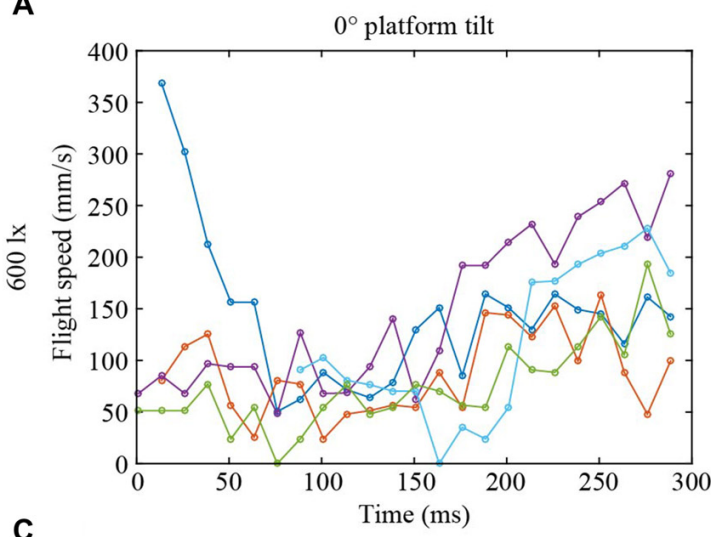

C
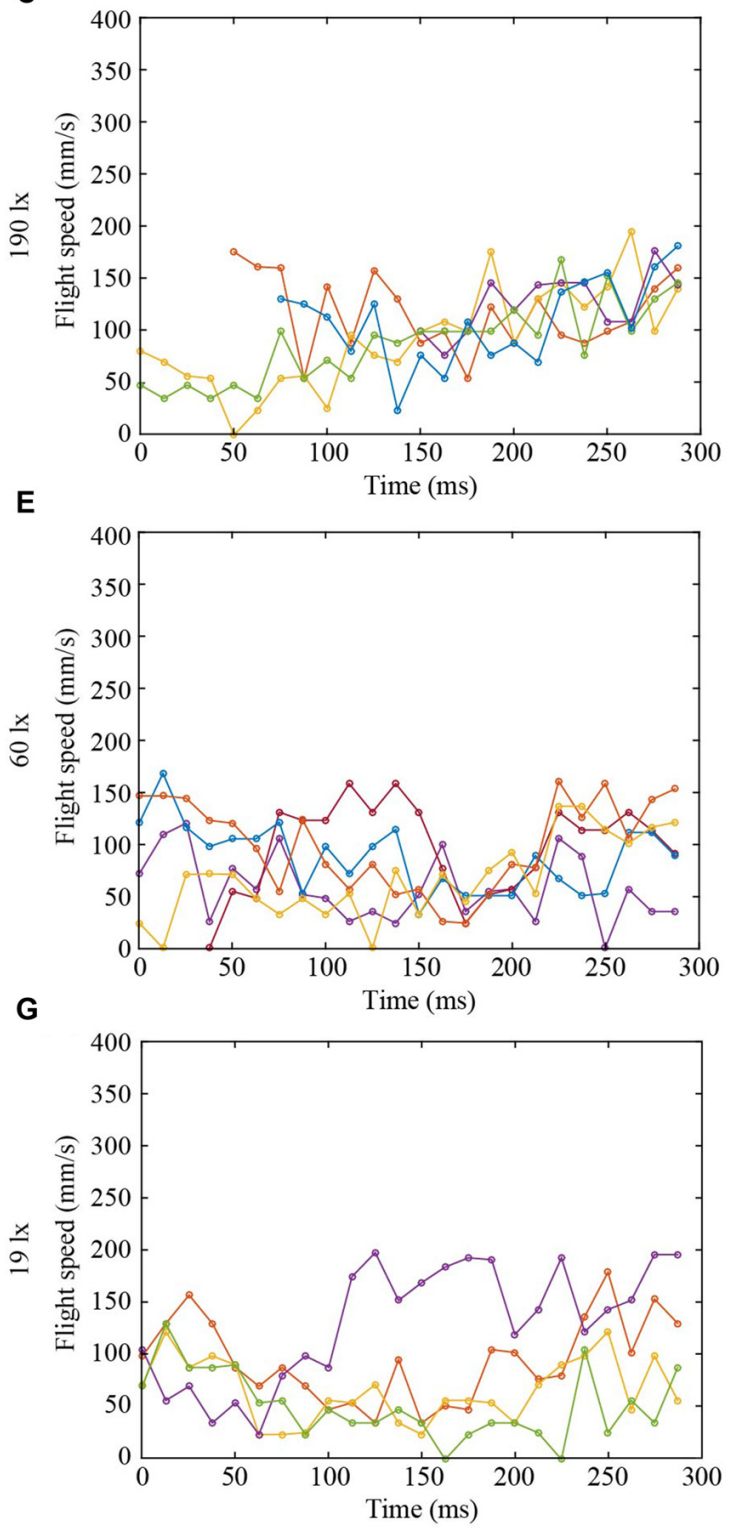

B

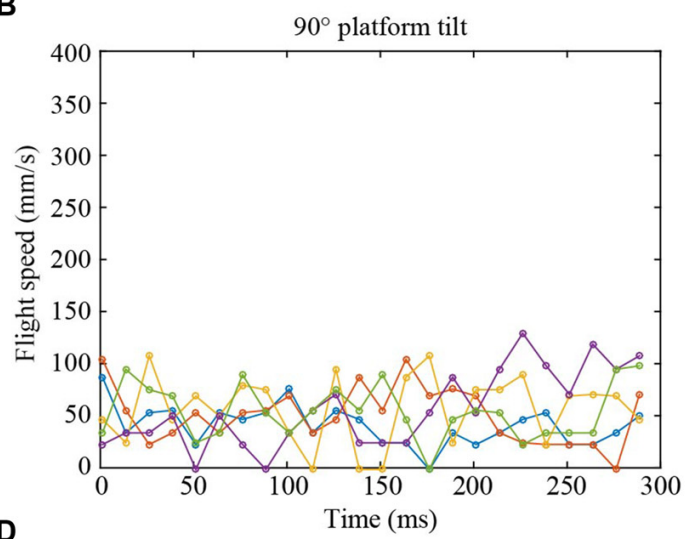

D

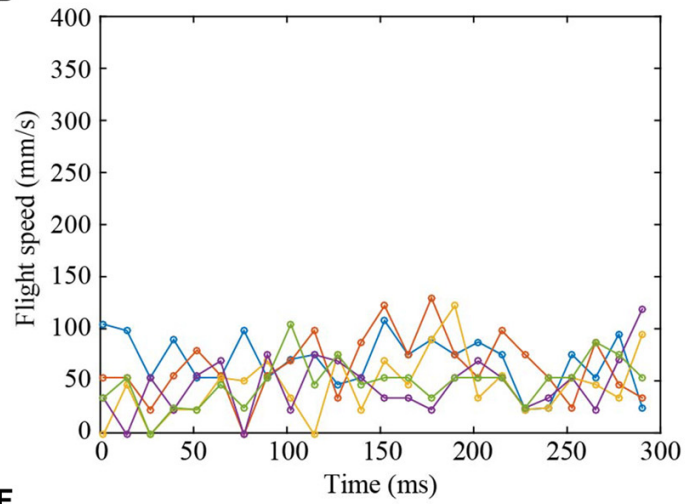

$\mathbf{F}$
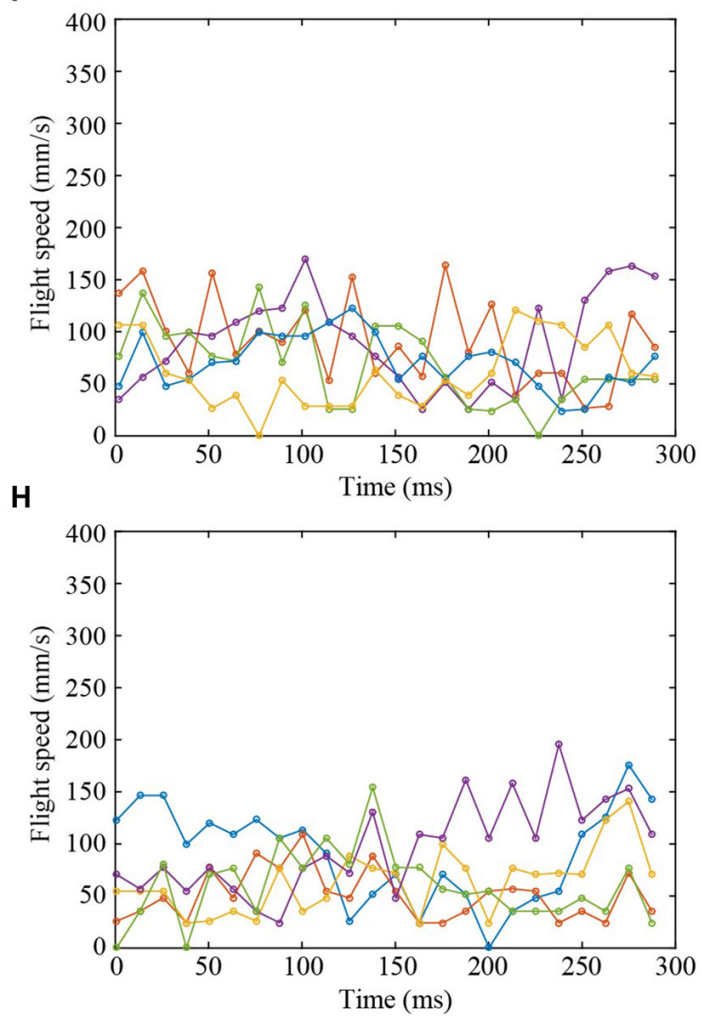

FIGURE 3 | Flight speed of landing bumblebees (same color in each graph in Figures 2, 3 represent the same bee) at different light intensities (A,B) $600 \mathrm{~lx},(\mathrm{C}, \mathrm{D}) 190 \mathrm{~lx},(\mathrm{E}, \mathrm{F}) 60 \mathrm{~lx},(\mathrm{G}, \mathrm{H}) 19 \mathrm{~lx}$, and platform tilts (A,C,E,G) $0^{\circ},(\mathrm{B}, \mathrm{D}, \mathrm{F}, \mathrm{H}) 90^{\circ}$. 

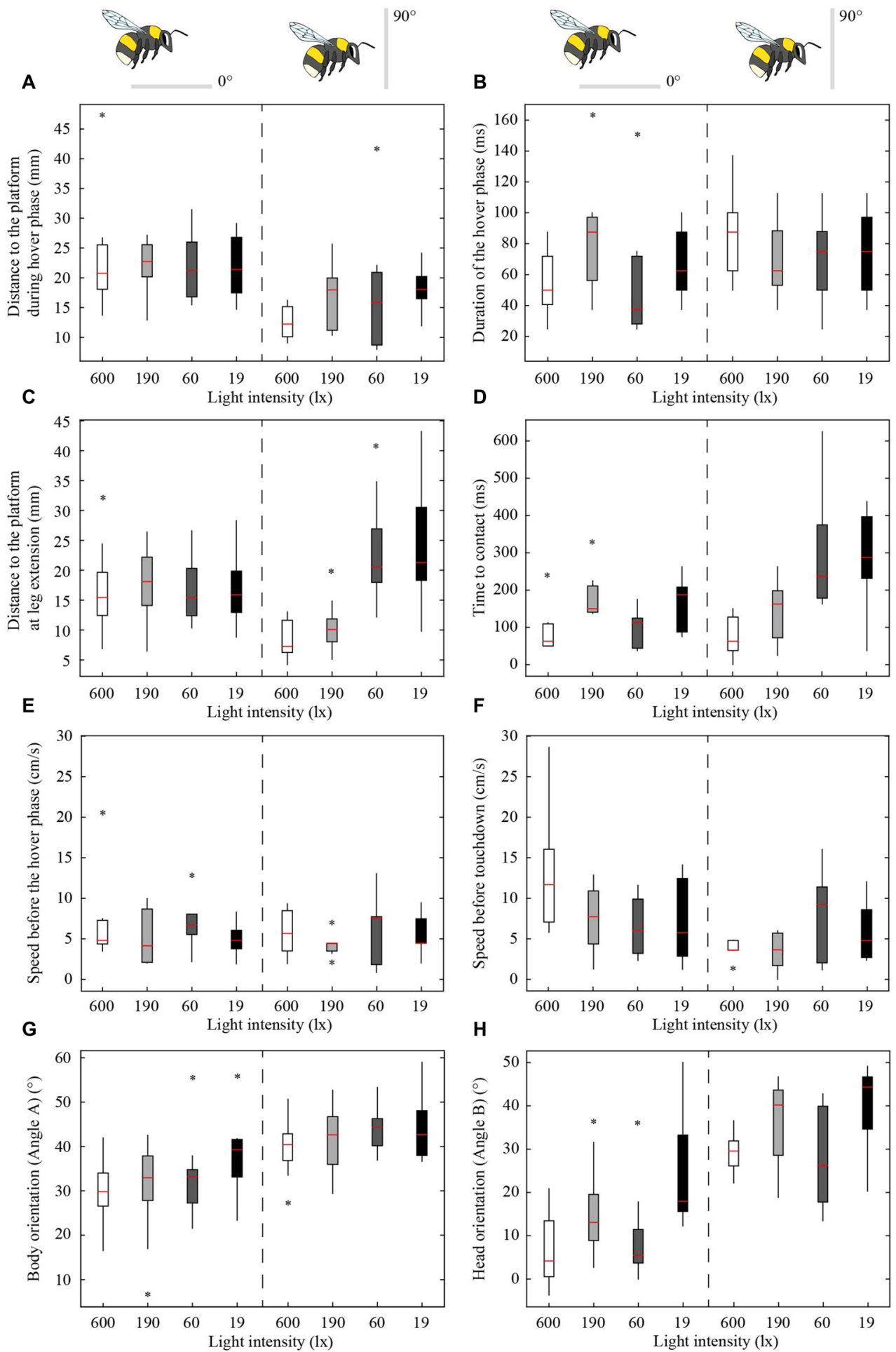

FIGURE 4 | Effect of light intensity and platform tilt on the distance to the platform during the hover phase (A) duration of the hover phase (B), distance to the platform at leg extension (C) time to contact (TTC; D) speed before the hover phase (E) speed before touchdown (F) body orientation $(\mathrm{G})$ and head orientation $(\mathrm{H})$ of bumblebees landing on a flat platform at two different orientations $\left(0^{\circ}\right.$ and $\left.90^{\circ}\right)$ and at four different light intensities $(\mathbf{1 9}, \mathbf{6 0}, \mathbf{1 9 0}$ and $\mathbf{6 0 0} \mathrm{lx})$. The schematic illustrations of the bees and the platforms indicate the orientation of the platform. The edges of the boxes denote the 25 th and 75 th percentiles, the central red mark is the median, the whiskers extend to the most extreme data points, and the black stars indicate outliers. For the number of analyzed individuals at each platform tilt and light intensity, see Table 2. 
TABLE 1 | Statistical details (test, factor, $F$-value and $P$-value) for measurements of landing performance of $B$. terrestris at platforms of different tilt $\left(0^{\circ}\right.$ and $90^{\circ}$ under different light intensities (ranging from $600 \mathrm{~lx}$ down to $19 \mathrm{~lx}$ ).

\begin{tabular}{|c|c|c|c|c|c|c|}
\hline Measurement & Statistical test & Factor & $\boldsymbol{F}$ & $P$ & LI (Ix) & Tilt $\left({ }^{\circ}\right)$ \\
\hline Distance to platform & Two-way ANOVA & Tilt* LI & 0.90 & 0.45 & & \\
\hline \multirow[t]{2}{*}{ during hover phase } & $"$ & Tilt & 10.70 & $<0.01$ & & \\
\hline & $"$ & LI & 0.20 & 0.90 & & \\
\hline Duration of & Two-way ANOVA & Tilt* LI & 1.19 & 0.32 & & \\
\hline \multirow[t]{4}{*}{ hover phase } & $"$ & Tilt & 0.92 & 0.34 & & \\
\hline & $"$ & $\mathrm{LI}$ & 0.49 & 0.69 & & \\
\hline & Two-way ANOVA & Tilt * LI & 12.24 & $<0.001$ & & \\
\hline & One-way ANOVA & $\mathrm{LI}$ & 0.12 & 0.95 & & 0 \\
\hline \multirow{7}{*}{$\begin{array}{l}\text { Distance to platform } \\
\text { at leg extension }\end{array}$} & $"$ & $"$ & 25.11 & $<0.001$ & & 90 \\
\hline & Post hoc (LSD) & LI & & 0.42 & $600-190$ & 90 \\
\hline & " & $"$ & & $<0.001$ & $600-60$ & $"$ \\
\hline & $"$ & $"$ & & 0.52 & 60-19 & $"$ \\
\hline & Two-way ANOVA & Tilt * LI & 4.71 & $<0.01$ & & \\
\hline & One-way ANOVA & $\mathrm{LI}$ & 3.35 & 0.036 & & 0 \\
\hline & $"$ & $"$ & 4.94 & 0.01 & & 90 \\
\hline Time to contact & Post hoc (LSD) & LI & & 0.020 & $600-190$ & 0 \\
\hline \multirow[t]{5}{*}{ from leg extension } & $"$ & $"$ & & 0.96 & $600-60$ & $"$ \\
\hline & $"$ & $"$ & & 0.07 & 60-19 & $"$ \\
\hline & $"$ & $"$ & & 0.37 & $600-190$ & 90 \\
\hline & $"$ & $"$ & & $<0.01$ & $600-60$ & $"$ \\
\hline & $"$ & $"$ & & 0.85 & $60-19$ & $"$ \\
\hline Flight speed prior & Two-way ANOVA & Tilt * LI & 0.24 & 0.87 & & \\
\hline \multirow[t]{2}{*}{ to hover phase } & $"$ & $\mathrm{LI}$ & 0.88 & 0.46 & & \\
\hline & Two-way ANOVA & Tilt * LI & 3.18 & 0.032 & & \\
\hline Flight speed prior & One-way ANOVA & $\mathrm{LI}$ & 2.09 & 0.13 & & 0 \\
\hline \multirow[t]{2}{*}{ to touchdown } & $"$ & $"$ & 1.98 & 0.14 & & 90 \\
\hline & Two-way ANOVA & Tilt * LI & 0.65 & 0.59 & & \\
\hline \multirow[t]{5}{*}{ Body angle (Angle A) } & $"$ & Tilt & 46.40 & $<0.001$ & & \\
\hline & $"$ & LI & 3.25 & 0.025 & & \\
\hline & Post hoc (LSD) & $\mathrm{LI}$ & & $<0.001$ & $600-19$ & \\
\hline & Two-way ANOVA & Tilt * LI & 0.86 & 0.47 & & \\
\hline & $"$ & Tilt & 121.03 & $<0.001$ & & \\
\hline \multirow[t]{4}{*}{ Head angle (Angle B) } & $"$ & LI & 14.62 & $<0.001$ & & \\
\hline & Post hoc (LSD) & $\mathrm{LI}$ & & $<0.01$ & $600-190$ & \\
\hline & $"$ & $"$ & & $<0.001$ & 190-19 & \\
\hline & $"$ & $"$ & & 0.84 & $600-60$ & \\
\hline
\end{tabular}

"=Same as above. For details on measurements, see "Materials and Methods" Section.

not when it was horizontal. As light levels decreased, the bees initiated leg extension further away from the vertical platform (from $8 \mathrm{~mm}$ to $24 \mathrm{~mm}$ from $600 \mathrm{~lx}$ to $19 \mathrm{~lx}$ ) but at a constant distance of 16-18 $\mathrm{mm}$ from the horizontal platform (Figure 4C, Table 1). The reason for this difference is unclear. It may be that, because the bees approach the vertical platform "head on", they are more careful when approaching it in the dark. This earlier leg extension might be a safety mechanism to compensate for possible errors in the estimate of the distance to the vertical platform. In contrast, such a mechanism would not be necessary when landing on the horizontal platform because the bees are not in danger of flying directly into it. We have recently shown that, as light intensity decreases, bumblebee photoreceptors sum photons over an increasingly longer time to enhance the sensitivity of their eyes (Reber et al., 2015). A consequence of this strategy is that fast-moving objects become blurred or disappear completely from the visual field of the bee (Warrant, 1999) and stationary objects that are approached (such as the platform) are detected with a longer time delay. By extending the legs further away from the vertically oriented platform, bumblebees might minimize the risk of crashing, an event that would occur if they do not initiate landing in time. Such a response would not be necessary when the platform is horizontal, as the bees are not approaching the surface head on.

As with the leg extension distance, light intensity had an effect on TTC for bees approaching the vertical platform (the mean TTC for the vertical platform significantly increased from $73 \mathrm{~ms}$ to $286 \mathrm{~ms}$ from $600 \mathrm{~lx}$ to $19 \mathrm{~lx}$ ), but not for the horizontal platform (TTC remained constant around $134 \mathrm{~ms}$ across all light levels). Because TTC is affected by both leg extension distance and speed, the increased TTC for the vertical platform may not only be due to an increased distance, but also due to a lower approach speed. However, the approach speed of the bees just before the hover phase $\left(6 \pm 3 \mathrm{~cm} \mathrm{~s}^{-1}\right.$, mean $\left.\pm \mathrm{SD}\right)$ and just before touchdown $\left(7 \pm 5 \mathrm{~cm} \mathrm{~s}^{-1}\right)$ did not differ across the light levels tested. Thus, the longer TTC recorded in dim light appears to simply be an effect of the greater distance at which leg extension is initiated. 
TABLE 2 | Number of different individuals analyzed for measurements of landing performance of $B$. terrestris under different light intensities (ranging from $600 \mathrm{~lx}$ down to $19 \mathrm{~lx}$ ) and two tilts of the landing platform $\left(0^{\circ}\right.$ and $\left.90^{\circ}\right)$.

\begin{tabular}{|c|c|c|c|c|c|c|c|c|}
\hline 니 (Ix) & Tilt $\left({ }^{\circ}\right)$ & $\mathbf{d}_{\mathrm{HP}}$ & dur $_{H P}$ & $d_{L E}$ & TTC & vPHP & $v$ PTD & $A, B$ \\
\hline \multirow[t]{2}{*}{600} & 0 & 7 & 7 & 16 & 7 & 7 & 7 & 16 \\
\hline & 90 & 7 & 7 & 16 & 6 & 7 & 7 & 16 \\
\hline \multirow[t]{2}{*}{190} & 0 & 7 & 7 & 16 & 7 & 6 & 7 & 16 \\
\hline & 90 & 7 & 7 & 16 & 5 & 7 & 7 & 16 \\
\hline \multirow[t]{2}{*}{60} & 0 & 7 & 7 & 15 & 7 & 6 & 7 & 15 \\
\hline & 90 & 7 & 7 & 16 & 7 & 7 & 7 & 16 \\
\hline \multirow[t]{2}{*}{19} & 0 & 7 & 7 & 7 & 7 & 7 & 7 & 7 \\
\hline & 90 & 7 & 7 & 16 & 7 & 7 & 7 & 16 \\
\hline
\end{tabular}

$d_{H P}$, distance to the platform during the hover phase; dur ${ }_{H P}$, duration of the hover phase; $d_{L E}$, distance to the platform at leg extension; $T$ TC, time to contact; $V_{P H P}$, mean flight speed prior to the hover phase; $V_{P T D}$, mean flight speed prior to touchdown; A, body orientation; B, head orientation. For details on measurements, see "Materials and Methods" Section.

The fact that the bees approached the platform at the same speed, irrespective of light level, provides some indication that their visual system is sensitive enough to perform wellcontrolled landings without adapting their landing flight speed, as they do when flying along experimental tunnels (Reber et al., 2015). However, an important difference between landing and cruising is that, when landing, the bees fly at a much lower speed $\left(6 \mathrm{~cm} \mathrm{~s}^{-1}\right.$ when landing vs. $89 \mathrm{~cm} \mathrm{~s}^{-1}$ when flying along a $30 \mathrm{~cm}$ wide tunnel). It is possible that, in the final touchdown phase of landing, the bumblebees have already reduced their speed to the lower limit of their range so that reducing it further provides no direct advantage. It is also possible that other adaptations to dim light such as the changes in distance of leg extension and body posture are sufficient for ensuring a safe touchdown without requiring a change of speed.

It is interesting to note that, in a recent study, Baird et al. (2015) also showed that light intensity had an effect on the TTC of bumblebees. In this earlier case, TTC decreased with light intensity, whereas here we observed the opposite effect. It is not clear why light intensity had a different effect in the two studies, but there are several important differences that might have played an important role. First, the behavioral context differed. In the present study, the bees were landing on a food source, while in Baird et al. (2015) they landed at the entrance of their nest. Hoverflies have been observed to approach flowers in a careful and meandering way if the goal is to feed but, if a possible mate is sitting on the surface of the flower, the fly instead accelerates towards the flower in a more direct way in the hope of courtship (Collett and Land, 1975). In a similar way, bees approaching a food source might do so more slowly and carefully than when approaching their nest. While an attempt to feed most likely includes a visual evaluation of the "flower" (Kevan, 1976; Zimmerman, 1982), landings at a familiar nest can be more direct and determined. Another factor that may have influenced the effect of light intensity on landing behavior in the two studies is the visual appearance of the platform. Baird et al. (2015) presented the bees with a $10 \mathrm{~cm}$ diameter disk that displayed a black and white concentric ring pattern, while in the present study, they were presented with a $1 \mathrm{~cm}$ diameter blue dot in the center of a $3 \mathrm{~cm}$ diameter white disk. These differences raise important questions about the effect of behavioral context and visual information on the landing behavior of bumblebees that will be addressed in future investigations.

\section{Vision Plays a Role in The Control of Body and Head Orientation During Landing}

Changes in light intensity affected both the body and head orientation of the landing bumblebees. As light intensity decreased, the bees oriented their bodies more vertically and their heads more horizontally with respect to the platform (Figures 4G,H, Table 1). Blowflies walking in complete darkness also tilt their heads and bodies more vertically in comparison to walks in bright light (Kress and Egelhaaf, 2012). This allows them to use their front legs as tactile probes by stretching them out in front of the body. Although the effect of light intensity on the head and body orientation of bumblebees was relatively small $\left(20^{\circ}\right.$ or less in most cases), it may represent a similar safety mechanism that allows the bees to make a precise legfirst touchdown, even when landing in very dim light. In fact, under the conditions presented in this study, not a single bee was observed to crash into the platform. The observation that body and head orientation are affected by changes in light intensity strongly suggests that these aspects of body posture are controlled by visual information, although exactly what visual information and how it is being used remains unclear.

\section{CONCLUSION}

Here, we have shown that light intensity has an effect on the timing of leg extension and the body posture of bumblebees landing on a flat platform at two different orientations $\left(0^{\circ}\right.$ and $90^{\circ}$ relative to the horizontal plane) and at four different light intensities (ranging from $600 \mathrm{~lx}$ down to $19 \mathrm{~lx}$ ). However, the changes in body posture are relatively small compared to the change in platform tilt $\left(90^{\circ}\right)$, and the landings are still well controlled even in dim light. The earlier leg extension combined with the changes in body posture might be a behavioral adaptation to dim light that allows the bees to make wellcontrolled landings across the broad range of light intensities at which they fly and forage. The consistent observation that light intensity affects the behavior of bumblebees in the final moments before touchdown provides a strong indication that landing is 
under predominantly visual control, although exactly what visual information is used and how remains unclear and will be the topic of future investigations.

\section{AUTHOR CONTRIBUTIONS}

TR performed the experiment and data analysis, and wrote the first draft of the manuscript. All authors (TR, MD, EW, EB) participated in the design of the experiment, the interpretation of the data and the final version of the manuscript.

\section{REFERENCES}

Baird, E., Boeddeker, N., Ibbotson, M. R., and Srinivasan, M. V. (2013). A universal strategy for visually guided landing. Proc. Natl. Acad. Sci. U S A 110, 18686-18691. doi: 10.1073/pnas.1314311110

Baird, E., Fernandez, D. C., Wcislo, W. T., and Warrant, E. J. (2015). Flight control and landing precision in the nocturnal bee Megalopta is robust to large changes in light intensity. Front. Physiol. 6:305. doi: 10.3389/fphys.2015.00305

Barlow, H. B. (1956). Retinal noise and absolute threshold. J. Opt. Soc. Am. 46, 634-639. doi: 10.1364/josa.46.000634

Borst, A. (1986). Time course of the houseflies' landing response. Biol. Cybern. 54, 379-383. doi: 10.1007/bf00355543

Collett, T. S., and Land, M. F. (1975). Visual control of flight behaviour in the hoverfly, Syritta pipiens L. J. Comp. Physiol. 99, 1-66. doi: 10.1007/bf01464710

De Vries, H. (1943). The quantum character of light and its bearing upon threshold of vision, the differential sensitivity and visual acuity of the eye. Physica. 10, 553-564. doi: 10.1016/s0031-8914(43)90575-0

Evangelista, C., Kraft, P., Dacke, M., Reinhard, J., and Srinivasan, M. V. (2009). The moment before touchdown: landing manoeuvres of the honeybee Apis mellifera. J. Exp. Biol. 213, 262-270. doi: 10.1242/jeb.037465

Goulson, D., Chapman, J. W., and Hughes, W. O. H. (2001). Discrimination of unrewarding flowers by bees; direct detection of rewards and use of repellent scent marks. J. Insect Behav. 14, 669-678. doi: 10.1023/A:1012231419067

Greiner, B., Ribi, W. A., and Warrant, E. J. (2004). Retinal and optical adaptations for nocturnal vision in the halictid bee Megalopta genalis. Cell Tissue Res. 316, 377-390. doi: 10.1007/s00441-004-0883-9

Johnsen, S., Kelber, A., Warrant, E., Sweeney, A. M., Widder, E. D., Lee, R. L., et al. (2006). Crepuscular and nocturnal illumination and its effects on color perception by the nocturnal hawkmoth Deilephila elpenor. J. Exp. Biol. 209, 789-800. doi: 10.1242/jeb.02053

Kelber, A., Warrant, E. J., Pfaff, M., Wallén, R., Theobald, J. C., Wcislo, W., et al. (2006). Light intensity limits the foraging activity in nocturnal and crepuscular bees. Behav. Ecol. 17, 63-72. doi: 10.1093/beheco/arj001

Kevan, P. G. (1976). Fluorescent nectar. Science 194, 341-342. doi: 10.1126/science. 194.4262 .341

Kress, D., and Egelhaaf, M. (2012). Head and body stabilization in blowflies walking on differently structured substrates. J. Exp. Biol. 215, 1523-1532. doi: $10.1242 /$ jeb.066910

Laughlin, S. B., and Lillywhite, P. G. (1982). Intrinsic noise in locust photoreceptors. J. Physiol. 332, 25-45. doi: 10.1113/jphysiol.1982.sp014398

Lillywhite, P. G. (1977). Single photon signals and transduction in an insect eye. J. Comp. Physiol. A 122, 189-200. doi: 10.1007/bf00611889

Lillywhite, P. G. (1981). Multiplicative intrinsic noise and the limits to visual performance. Vision Res. 21, 291-296. doi: 10.1016/0042-6989(81)90123-1

Lillywhite, P. G., and Laughlin, S. B. (1979). Transducer noise in a photoreceptor. Nature 277, 569-572. doi: 10.1038/277569a0

Reber, T., Baird, E., and Dacke, M. (2016). The final moments of landing in bumblebees, Bombus terrestris. J. Comp. Physiol. A 202, 277-285. doi: 10. 1007/s00359-016-1073-4

Reber, T., Vähäkainu, A., Baird, E., Weckström, M., Warrant, E., and Dacke, M. (2015). Effect of light intensity on flight control and temporal properties of photoreceptors in bumblebees. J. Exp. Biol. 218, 1339-1346. doi: 10.1242/jeb. 113886

\section{FUNDING}

This work was supported by the Swedish Research Council Formas [229-2010-829], the Swedish Foundation for Strategic Research [FFL09-0056], and the Swedish Research Council [2011-4701, 2014-44295-114711-25].

\section{ACKNOWLEDGMENTS}

We wish to thank Lana Khaldy for assistance with data analysis.

Rose, A. (1942). The relative sensitivities of television pickup tubes, photographic film and the human eye. Proc. Inst. Radio Eng. 30, 293-300. doi: 10.1109/jrproc. 1942.230998

Rose, R., and Menzel, R. (1981). Luminance dependence of pigment color discrimination in bees. J. Comp. Physiol. A 141, 379-388. doi: 10 . 1007/bf00609940

Somanathan, H., Borges, R. M., Warrant, E. J., and Kelber, A. (2008). Visual ecology of Indian carpenter bees I: light intensities and flight activity. J. Comp. Physiol. A 194, 97-107. doi: 10.1007/s00359-0070291-1

Spaethe, J., and Weidenmüller, A. (2002). Size variation and foraging rate in bumblebees (Bombus terrestris). Insect. Soc. 49, 142-146. doi: 10.1007/s00040002-8293-Z

Spiewok, S., and Schmolz, E. (2005). Changes in temperature and light alter the flight speed of hornets (Vespa crabro L.). Physiol. Biochem. Zool. 79, 188-193. doi: $10.1086 / 498181$

Sponberg, S., Dyhr, J. P., Hall, R. W., and Daniel, T. L. (2015). Luminancedependent visual processing enables moth flight in low light. Science 348, 1245-1248. doi: 10.1126/science.aaa3042

Srinivasan, M. V., Zhang, S. W., Chahl, J. S., Barth, E., and Venkatesh, S. (2000). How honeybees make grazing landings on flat surfaces. Biol. Cybern. 83, 171-183. doi: 10.1007/s004220000162

Tammero, L. F., and Dickinson, M. H. (2002). Collision-avoidance and landing responses are mediated by separate pathways in the fruit fly, Drosophila melanogaster. J. Exp. Biol. 205, 2785-2798.

van Breugel, F., and Dickinson, M. H. (2012). The visual control of landing and obstacle avoidance in the fruit fly Drosophila melanogaster. J. Exp. Biol. 215, 1783-1798. doi: 10.1242/jeb.066498

Wagner, H. (1982). Flow-field variables trigger landing in flies. Nature 297, 147-148. doi: 10.1038/297147a0

Warrant, E. J. (1999). Seeing better at night: life style, eye design and the optimum strategy of spatial and temporal summation. Vision Res. 39, 1611-1630. doi: 10. 1016/s0042-6989(98)00262-4

Warrant, E. J., Kelber, A., Gislén, A., Greiner, B., Ribi, W., and Wcislo, W. T. (2004). Nocturnal vision and landmark orientation in a tropical halictid bee. Curr. Biol. 14, 1309-1318. doi: 10.1016/j.cub.2004.07.057

Warrant, E. J., and McIntyre, P. D. (1993). Arthropod eye design and the physical limits to spatial resolving power. Prog. Neurobiol. 40, 413-461. doi: 10 1016/0301-0082(93)90017-m

Zimmerman, M. (1982). Optimal foraging: random movement by pollen collecting bumblebees. Oecologia 53, 394-398. doi: 10.1007/bf003 89020

Conflict of Interest Statement: The authors declare that the research was conducted in the absence of any commercial or financial relationships that could be construed as a potential conflict of interest.

Copyright (c) 2016 Reber, Dacke, Warrant and Baird. This is an open-access article distributed under the terms of the Creative Commons Attribution License (CC BY). The use, distribution and reproduction in other forums is permitted, provided the original author(s) or licensor are credited and that the original publication in this journal is cited, in accordance with accepted academic practice. No use, distribution or reproduction is permitted which does not comply with these terms. 